\title{
Main Challenges and Goals of the H2020 STRATOFLY Project
}

\author{
Nicole Viola ${ }^{1}$ (D) Roberta Fusaro ${ }^{1} \cdot$ Bayindir Saracoglu ${ }^{2} \cdot$ Christophe Schram $^{2} \cdot$ Volker Grewe $^{3}$ - Jan Martinez ${ }^{4}$. \\ Marco Marini ${ }^{5}$. Santiago Hernandez ${ }^{6} \cdot$ Karel Lammers $^{7} \cdot$ Axel Vincent $^{8} \cdot$ Didier Hauglustaine $^{9} \cdot$ Bernd Liebhardt $^{10}$. \\ Florian Linke $^{10}$. Christer Fureby ${ }^{11}$
}

Received: 5 July 2020 / Revised: 11 May 2021 / Accepted: 15 May 2021 / Published online: 29 May 2021

(C) The Author(s) 2021

\begin{abstract}
As eluded in previous studies, with special reference to those carried out in the European framework, some innovative highspeed aircraft configurations have now the potential to assure an economically viable high-speed aircraft fleet. They make use of unexploited flight routes in the stratosphere, offering a solution to the presently congested flight paths while ensuring a minimum environmental impact in terms of emitted noise and green-house gasses, particularly during stratospheric cruise. Only a dedicated multi-disciplinary integrated design approach could realize this, by considering airframe architectures embedding the propulsion systems as well as meticulously integrating crucial subsystems. In this context, starting from an in-depth investigation of the current status of the activities, the STRATOFLY project has been funded by the European Commission, under the framework of Horizon 2020 plan, with the aim of assessing the potential of this type of high-speed transport vehicle to reach Technology Readiness Level (TRL) 6 by 2035, with respect to key technological, societal and economical aspects. Main issues are related to thermal and structural integrity, low-emissions combined propulsion cycles, subsystems design and integration, including smart energy management, environmental aspects impacting climate change, noise emissions and social acceptance, and economic viability accounting for safety and human factors. This paper aims at summarizing the main challenges and goals of the STRATOFLY project, highlighting the steps forward with respect to the past European Projects and underlying the next planned goals.
\end{abstract}

Keywords High-speed transportation · Technological challenges $\cdot$ Environmental sustainability

Roberta Fusaro

nicole.viola@polito.it

1 Mechanical and Aerospace Engineering Department, Politecnico di Torino, Corso Duca degli Abruzzi 24, 10129 Turin, Italy

2 Von Karman Institute for Fluid Dynamics, Waterloosesteenweg 72, 1640 Sint-Genesius-Rode, Belgium

3 Institut für Physik der Atmosphäre, Deutsches Zentrum für Luft- und Raumfahrt (DLR) Oberpfaffenhofen, Münchner Straße 20, 82234 Wessling, Germany

4 Institute of Aerodynamics and Flow Technology, Deutsches Zentrum Für Luft- Und Raumfahrt (DLR) Oberpfaffenhofen, Münchner Straße 20, 82234 Wessling, Germany

5 Centro Italiano Ricerche Aerospaziali, Via Maiorise, 81043 Capua, CE, Italy
6 Department of Construction Technology, University of La Coruna, Rúa da Maestranza 9, 15001 A Coruña, Spain

7 Netherlands Aerospace Centre, Anthony Fokkerweg 2, 1059 CM Amsterdam, The Netherlands

8 Department of Multi-Physic for Energetics, The French Aerospace Lab ONERA, R91123 Palaiseau, France

9 Laboratoire des Sciences du Climat et de l'Environnement (LSCE), CNRS, Gif-sur-Yvette CEDEX, France

10 Technical University of Hamburg Harburg, Am Schwarzenberg-Campus, 21073 Hamburg, Germany

11 Lund University, Department of Energy Sciences / Heat Transfer, SE-221 00 Lund, Sweden 


\section{Introduction}

The worldwide incentive to reconsider commercial highspeed transport urges Europe to quantitatively assess the potential of civil high-speed aviation with respect to technical, environmental and economic viability in combination with human factors, social acceptance, implementation and operational aspects. High-speed commercial flights could be significantly beneficial for long-haul routes to virtually shrink the globe and shorten the time of flight of one order of magnitude for antipodal destinations, thus revolutionizing the present idea of business trips and touristic travels. The satisfaction of this need can, however, be seriously hampered by the compliance with the environmental sustainability requirements that currently represent the main goal for aviation, unless innovative technological solutions are investigated, developed and eventually integrated and validated in operative aircraft. Generally speaking, the higher is the speed of flight, the higher is the fuel consumption and consequently emissions, unless breakthrough technologies can intervene to break down this obvious conclusion. To allow for lowenvironmental impact and de-carbonization of air travels by 2050 , new solutions need to be designed for the various ranges of flight routes, thus leading to different aircraft configurations and enabling technologies for short, medium and long-haul range missions.

As far as long-haul flights are concerned, the targets of zero $\mathrm{CO}_{2}$ emissions and shorter times of flight urge to seek for new solutions in terms of propellant, aircraft configuration and technologies. To shorten the time of flight and to fulfill the requirement of long-haul routes, high-speed airbreathing propulsion shall be considered, innovative aircraft configuration with high aerodynamic efficiency shall be targeted [1] and liquid hydrogen, that guarantees complete decarbonization, shall be exploited as not drop-in fuel, thanks to its high specific energy content. Shorter time of flights and long-haul routes are the two crucial mission requirements that have led to a new concept of aircraft for high-speed long-haul routes that has been named STRATOFLY MR3. STRATOFLY MR3 is the reference vehicle of the H2020 STRATOFLY project, a highly multidisciplinary project, funded by European Commission within the framework of the Horizon 2020 Program. STRATOFLY is the natural follow-on of a series of European Projects (i.e. ATLLAS I/ II [2], LAPCAT I/II [3], HIKARI [4], HEXAFLY [5], HEXAFLY Int. [6]) devoted to study the feasibility of the highspeed civil transportation at stratospheric altitudes, with the goal to reduce the duration of antipodal flights of one order of magnitude with respect to current air transport.

Main project objectives are to refine the design and the concept of operations of STRATOFLY MR3 vehicle throughout all mission phases, including the crucial subsonic and transonic regimes, reaching the ambitious goal of Technology Readiness Level (TRL) $=6$ by 2035 for the concept, developing crucial technologies which may represent a step forward for future reusable space transportation systems.

After the introduction, the paper proceeds with Sect. 2 with a description of STRATOFLY MR3 and its reference mission, then in Sect. 3 technical challenges are analyzed and conflicting requirements are highlighted. Eventually main conclusions are drawn.

\section{STRATOFLY MR3}

The concept of a hypersonic aircraft makes sense only for long-haul routes with ranges up to antipodal destinations because long-haul routes maximize the benefits of a hypersonic cruise at Mach 8, while medium-haul routes suffer from shorter cruise phases.

Simply based on the Breguet range equation (see Eq. 1), if the design is driven by the mission requirement of long-haul routes, higher ranges can be achieved thanks to higher values of $L / D$, in combination with higher energy per unit of fuel mass $\left(\Delta h_{f}\right)$, higher propulsive system efficiency and higher value for the ratio of initial mass with respect to final mass.

$R=\frac{\Delta h_{f}}{g} \eta_{\text {overall }} \frac{L}{D} \ln \left(\frac{W_{\text {initial }}}{W_{\text {final }}}\right)$

Therefore, to match the mission requirement of long-haul routes, the waverider configuration has been selected for the STRATOFLY MR3 vehicle to guarantee higher $L / D$ values $(L / D>6)$, liquid hydrogen is exploited as propellant for its higher specific energy with respect to hydrocarbon and light weight bubble structures are considered to allow for higher ratios of initial mass with respect to final mass.

The second crucial mission requirement of shorter time of flights (the time of flight shall be shortened of one order of magnitude with respect to current values) leads to the exploitation of high-speed air-breathing engines up to ramjet and scramjet modes of operations. Specifically, STRATOFLY MR3 integrates 6 Air Turbo Rocket engines, ATR, that operate up to Mach 4-4.5 and one Dual Mode Ramjet, DMR, that is used for hypersonic flight from Mach 4.5 up to Mach 8.

It is worth remembering that the use of liquid hydrogen guarantees complete de-carbonization, thus fulfilling another top mission requirement.

As a consequence, it can be stated that STRATOFLY MR3 vehicle is driven by its peculiar mission, which can be summarized as follows: STRATOFLY MR3 shall be able to fly along antipodal route $(R>16,000 \mathrm{~km})$ reaching Mach 8 


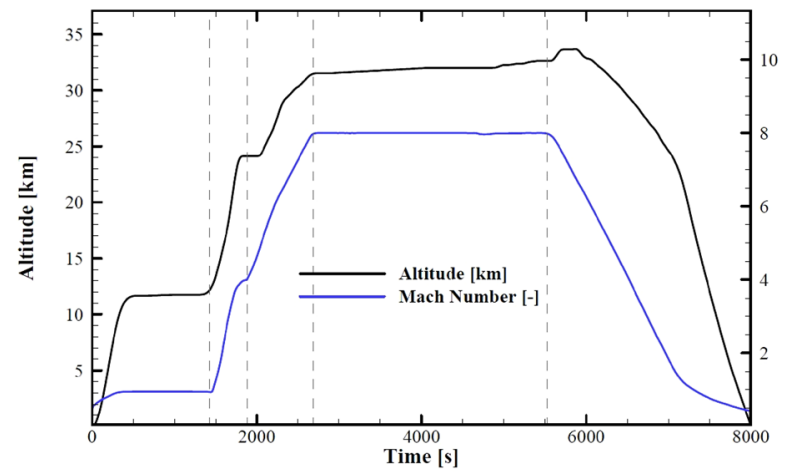

Fig. 1 STRATOFLY MR3 reference trajectory in terms of altitude versus time and Mach number versus time

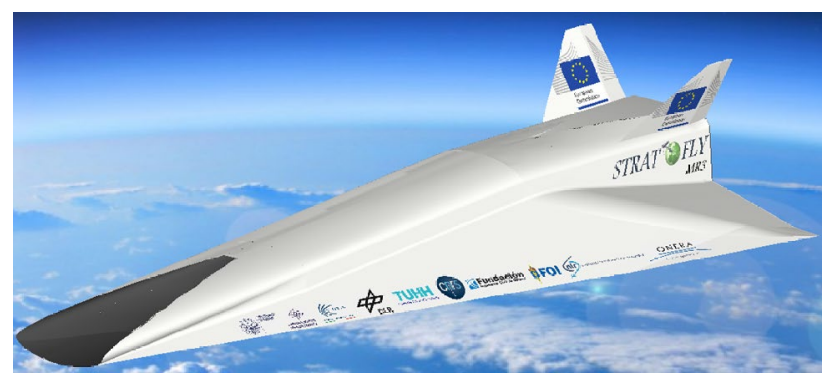

Fig. 2 STRATOFLY MR3 external configuration

during cruise at a stratospheric altitude $(h>30,000 \mathrm{~m})$ carrying 300 passengers as payload. Figure 1 depicts the trajectory of STRATOFLY MR3.

Figure 2 shows STRATOFLY MR3 external configuration.

As already mentioned, STRATOFLY MR3 has a waverider configuration with the engines and related air duct embedded into the airframe and located at the top. The integration of the propulsive system at the top of the vehicle allows to maximize the available planform for lift generation without additional drag penalties and to optimize the internal volume. This layout guarantees furthermore to expand the jet to a large exit nozzle area without the need to perturb the external shape which would lead to extra pressure drag.

Main technical data about STRATOFLY MR3 are reported in Table 1.

Within the H2020 STRATOFLY Project, along with traditional conceptual design activities, the consortium explores and suggests innovative methodologies for the validation of highly complex and highly integrated vehicle and mission concepts since the very early stage of design. In particular, benefitting from the detailed investigations carried out by the specialists on the most impacting subsystems and technologies, more precise routines for the estimation of mass, volume and power budgets are currently under development.
Table 1 STRATOFLY MR3 main technical data

\begin{tabular}{lcl}
\hline Technical data & Value & $\begin{array}{l}\text { Unit of } \\
\text { measure- } \\
\text { ment }\end{array}$ \\
\hline Length & 94 & $\mathrm{~m}$ \\
Wing span & 41 & $\mathrm{~m}$ \\
Height & 17 & $\mathrm{~m}$ \\
Maximum take-off gross weight & 400 & tons \\
Overall volume & 10,000 & $\mathrm{~m}^{3}$ \\
Fuel weight & 200 & tons \\
Maximum thrust at take-off & 3070 & $\mathrm{kN}$ \\
Thrust during cruise & 500 & $\mathrm{kN}$ \\
\hline
\end{tabular}

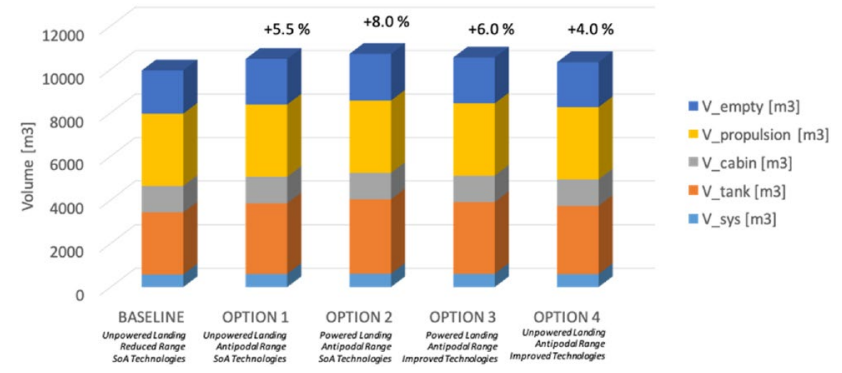

Fig. 3 Different options for STRATOFLY MR3 internal volumes distribution and overall volume differences between the options lie in unpowered versus powered landing, reduced versus antipodal range and state of the art versus improved technologies

The application of these routines to STRATOFLY MR3 vehicle is planned to be carried in the last part of the project when a refined vehicle and mission concept baseline will be presented. Currently, different options appear viable both from the vehicle as well as from the mission standpoint and are under investigations. Figure 3 shows an example of different vehicle baselines which have a different overall available volume and internal volume distribution. Differences between the options are related to the adoption of slightly different mission concepts (such as different landing strategies, reduced versus antipodal range) and slightly different propellant storage technologies concepts (i.e. state of the art versus futured improved technologies). In this case, data coming from specialists in aerodynamics, propulsion and flight controls are used to perform a new set of mission simulations and the results will be used to quantitative estimate Figures of Merits to be eventually used in a trade-off methodology. Similarly, experts from the propulsion and propellant domains will provide finer mass and volume estimations for different storage options to allow for a finer parametrization of the complex tanks' geometry on the 3D CAD model. These set activities will aim at providing analytical methods for the estimation of the impact of different propellant 


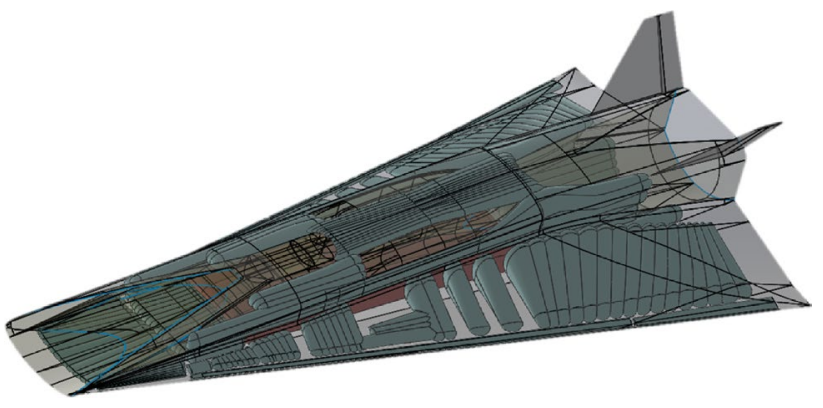

Fig. 4 STRATOFLY MR3 internal layout

storage technologies on the vehicle volume. Similarly, mass and power design spaces will be further investigated thanks to specialists' analyses and simulations and a final baseline concept will be suggested.

\section{STRATOFLY MR3: Techinal Challenges and Goals}

STRATOFLY MR3 is a highly integrated system, where propulsion, aerothermodynamics, structures and on-board subsystems are strictly interrelated one another, as Fig. 4 highlights.

The multidisciplinary design methodology developed in the framework of the H2020 STRATOFLY Project and currently under implementation aims at guaranteeing a reliable convergence toward the selection of a vehicle and mission concept baseline. To achieve this goal, the project approaches the topic from two different but complementary design spaces: the operational design versus high-speed aircraft and technology design. The operational design space defines the possibilities and requirements for high-speed transportation from a socio-economic and environmental viability perspective, whereas the high-speed aircraft and technology design space assesses and provides the related performances and capabilities required for attainable highspeed aircraft concepts and propulsion systems. Therefore, the methodology defined in the H2020 STRATOFLY shall assure that an overall optimum and a societal acceptable implementation of a high-speed aircraft fleet can be accomplished with realizable technologies. In details, within the operational design space, various modes of high-speed transportation are evaluated in a parametric way with respect to environmental sustainability, economic viability and overall safety aspects. These evaluations deeply impact the design of the aircraft and impose the elicitation of a complete set of requirements. Complementary, the focus in the technology design space is on optimizing high-speed aircraft concept(s) at vehicle, and subsystem level. Integration of multi-functioning subsystems from the structures to the on-board life support systems is investigated to target efficient operations. In this context, as properly addressed in the following sections of the paper, special efforts are devoted to enhancing the propulsive and aerothermodynamic performance of the vehicle by fully or partially embedding the propulsion system(s) into the aircraft airframe.

Main technical challenges of the STRATOFLY MR3 vehicle are described in the following sections, with a focus on the crucial enabling technologies that potentially representing a step forward and directly applicable to the reusable ascent and re-entry space transportation systems.

\subsection{Multi-bubble Multi-functional Structures}

The use of dual or multiple bubble structure is exploited for an overall stiff architecture at a lower mass fraction, to achieve lightweight structures with multi-functional roles, such as passenger cabin, multiple split tanks with anti-slosh baffles, engine bays, intake flowpaths, etc., to eventually integrate all subsystems in an harmonious way. This concept, already explored in the $70 \mathrm{~s}$, can nowadays be studied more into the details thanks to available design and analysis tools.

The multi-bubble concept is applied to almost every zone of the STRATOFLY MR3, including the passengers' cabin and the front, lateral and rear cryogenic fuel tanks (see Fig. 5). The structure model was generated using the ABAQUS software and is composed of a finite element mesh of about 1,600,000 shell elements. Such large number is due to the need to discretize with enough fidelity each part of the vehicle. Three materials are defined in the model: aluminium 2195 for the cryogenic tanks, CFRD in the passenger cabin

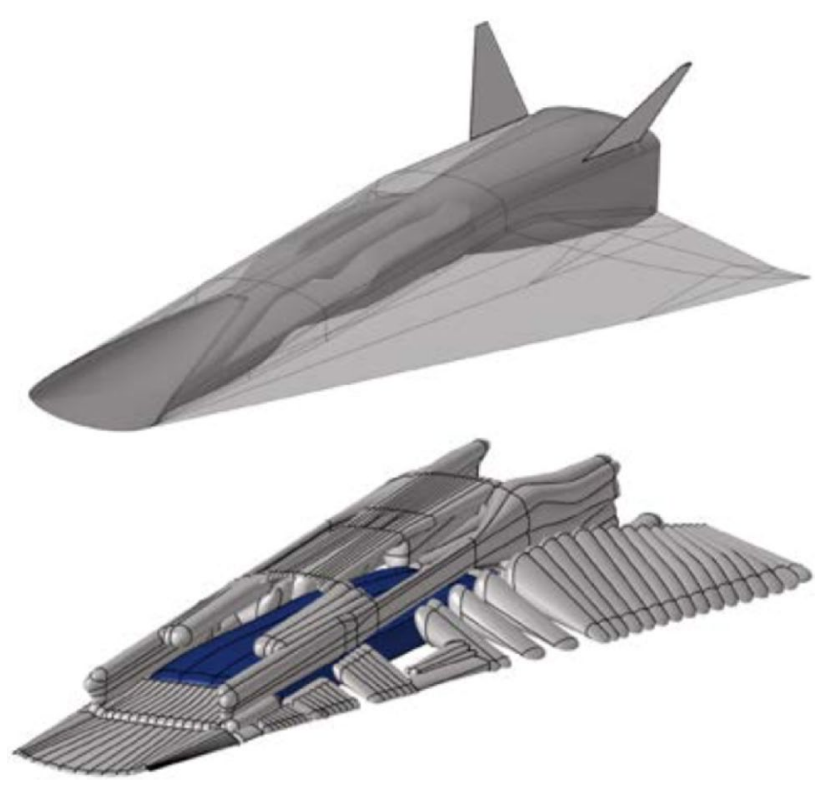

Fig. 5 STRATOFLY MR3 multi-bubble multi-functional structure 
and CMC in the DMR and outer skin. The classes of loads considered in the structural analysis are very diverse and appear in Table 2 and additionally modal analysis will be carried out to find out the eigenvalues and eigenvectors of the vehicle.

The multi-objective optimization takes into account several engineering fields, such as noise, aerodynamic and thermal loads. Figure 6 shows the flowchart of the process. The inputs from other fields than structural analysis consist on surrogate models that are function of the design variables of the optimization process namely the thicknesses of the structural components of the vehicle. Thickness modifications of the structural elements alter the mass of the vehicle and decrease the lift and thrust forces needed. In addition, changes in mass and thrust affect noise contours [16].

That approach will allow to carry out a multi-disciplinary optimization formulation considering not only the mass of the vehicle as objective function but also other properties as noise level or fuel consumption. The results of the procedure will be the Pareto front as presented in the figure that will allow the trade-off studies between the objective functions according to the priorities of the designer.

\subsection{High-Speed Propulsion}

Propulsion system performance will be improved and optimized paying special attention to take-off, engine transition and landing, landing as they are the most challenging flight conditions for this propulsion system and the hypersonic aircraft. The required thrust levels for the take-off must be ensured by six ATR engines through meticulous optimization process. The transition phase between the ATR an DMR engines also needs special attention during the optimization due to the unusual flight Mach numbers for turbomachinerybased aircraft engines in general, while the DMR at ramjet mode has to be ready to deliver required thrust for the vehicle experiencing engine transition. The exhaust nozzle/airframe integration will be investigated to reduce noise levels both at cruise and during transient operation at low speeds

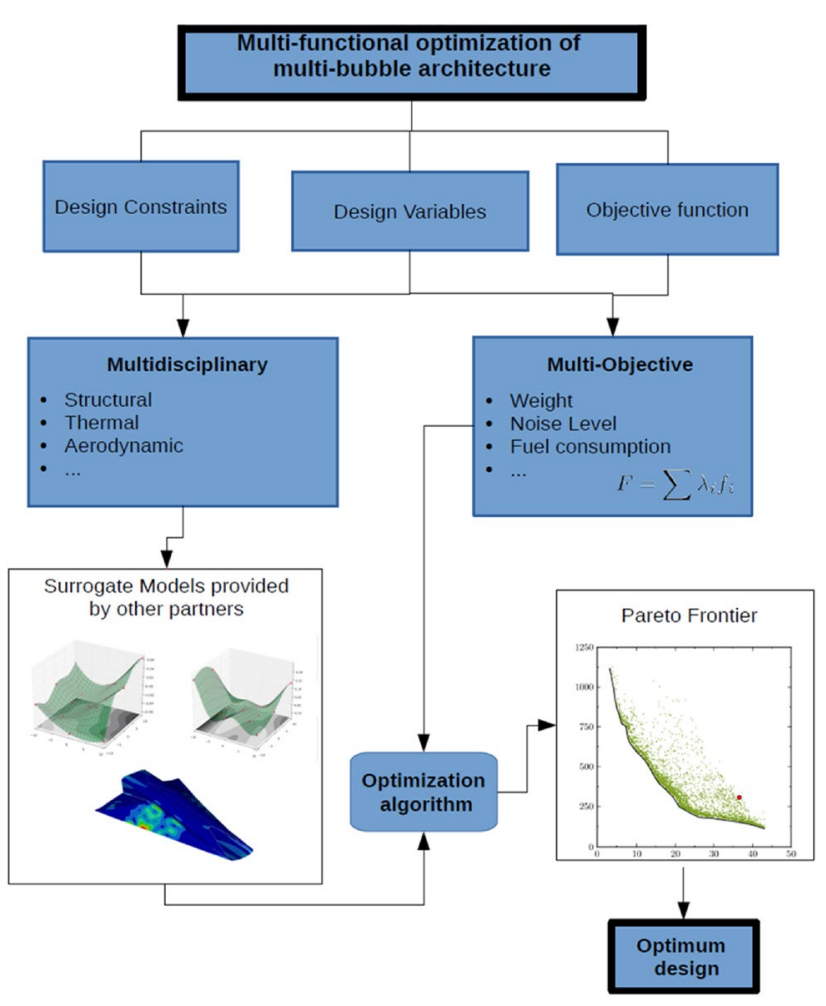

Fig. 6 Flowchart of multi-objective multidisciplinary optimization

thanks to the detailed aeroacoustic experiments of the dualflow path nozzle and theoretical studies on the test results aiming at proposing flow control techniques and methods to reduce the noise radiation within the structure of the aircraft. The DMR combustor will be optimized in terms of the mixing efficiency and combustion zone within the DMR duct to reduce NOx emissions, thanks to both engineering and CFD tools, and by exploiting dedicated experiments at DLR-HEG. The current configuration of fuel injection struts will be altered so that the complete fuel mixing and high combustion efficiency are achieved while the residence time of the reacting mixture is reduced under conditions favorable for NOX production inside the combustor section.
Table 2 Loads applied to STRATOFLY-MR3 vehicles

\begin{tabular}{lll}
\hline Type of load & Load & Modeling \\
\hline Dead & Vehicle weight & Material density \\
& Passenger load & Landing gear \\
& Fuel weight & Concentrated mass \\
& Cabin pressurization & Hydrostatic pressure \\
Internal pressures & Fuel tanks pressure & Uniform pressure \\
External aerodynamic & Skin aerodynamic load & \\
& $\begin{array}{l}\text { Resultant forces on empennages } \\
\text { Engine pressures }\end{array}$ & Engine inlet, combustion chamber and \\
& nozzle loads & Interpolated pressure field \\
Thermal & Thermal load on engine and skin & Interpolated temperature field \\
\hline
\end{tabular}


Consequently, the reactive fuel air mixture shall be expanded inside the nozzle and flow temperatures promoting the NOX reactions shall be quenched during the acceleration of the flow.

The propulsion plant of STRATOFLY MR3 aircraft consists of an air-breathing engine which is a combination of air turbo rockets (ATR) and a dual mode ramjet (DMR) engine. There are six ATR engines positioned around the DMR engine, and they are responsible to propel the aircraft during take-off, subsonic cruise and supersonic acceleration (Mach $0 \div 4.5$ ). The DMR in its ramjet mode kicks in after cruise speed of Mach 1.5, and starts to contribute to thrust level in a gradually increasing fashion as the flight Mach number increases. At the cruise speed of Mach 4.5, ATR engines are completely shut down and the DMR engine only provides the thrust. Both engine bays share common intake and nozzle sections. Incoming air is split-up in two streams going to ATR engine bays and DMR engine inside the inlet prior the DMR isolator. Exhaust flows coming from both engines merge in a common nozzle downstream of DMR combustor outlet.

Each ATR engine includes air-compressor, turbo-pump, fuel turbine, pre-burner and regenerator system. The fuel turbine is responsible to drive the air-compressor and fuel pump, while regenerators locating around the pre-burner and nozzle picks up heat to increase enthalpy of the fuel flow before it goes into the turbine. The regenerators should have enough capacity for heat pick-up so that turbine can produce the required shaft power for the air-compressor and pump.

DMR engine consists of four main components, i.e. supersonic-hypersonic intake, isolator, combustor and nozzle. During the supersonic cruise, it operates in ramjet mode and fuel-air mixture is burned under subsonic conditions. The hot combustion products accelerate sonic conditions in the end of the DMR combustor so that flow reaches thermal choking conditions during the cruise between Mach 1.5 and 4.5. Beyond this point, the flow inside the DMR remains fully supersonic throughout the engine.

A one-dimensional propulsion model for MR3 vehicle's propulsion plant (see Fig. 7) was built in EcoSimPro [7], a transient thermodynamic propulsion simulation platform, to estimate combined ATR and DMR engines performance along the subsonic cruise and supersonic acceleration parts of flight trajectory.

The EcoSimPro software is a multi-disciplinary simulation platform, with components in the continuous system modeled using various mathematical relations describing their physical behavior [8]. The software also enables implementation of several libraries such as European Space Propulsion System Simulation (ESPSS) to model specific systems, such as rocket propulsion components [7]. An optimization study is being performed at VKI by coupling EcoSimPro and Computer Aided Design and Optimization

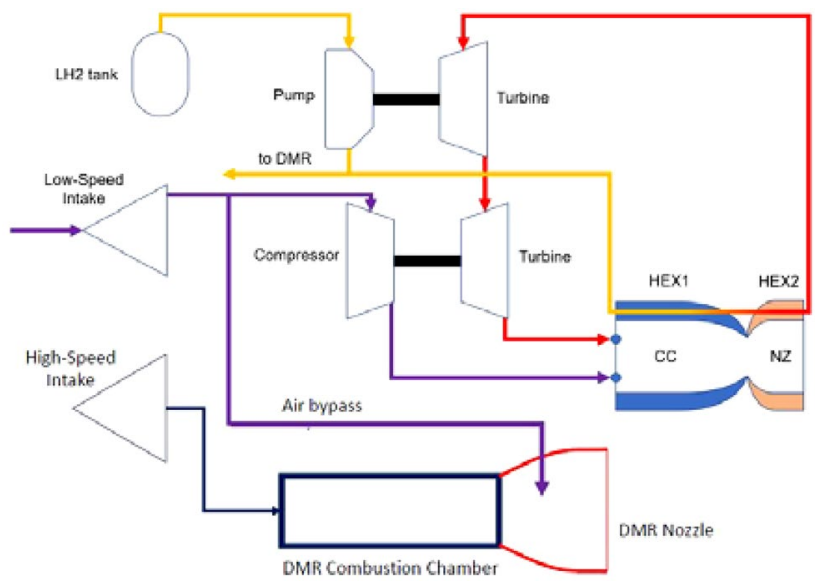

Fig. 7 Schematics of ATR and DMR engine layout

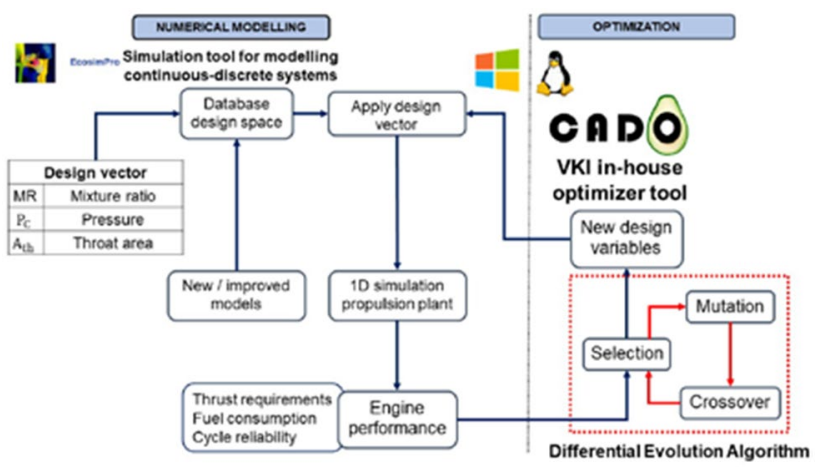

Fig. 8 Sketch of optimization methodology

tool (CADO), see Fig. 8, to obtain optimal boundary and operational conditions for the best performance values, such as specific thrust and impulse at minimum fuel consumption. CADO is an in-house code optimizer developed at VKI, with the Darwinian Theory based optimization routine [9], which includes evolution algorithm consisting of selection, mutation and crossover.

By evaluating the engine performance with this algorithm, new design variables are determined, and simulations are repeated in the EcoSimPro. Design variables are determined as air-fuel mixture ratio, combustion chamber pressure and chamber throat area, since most conditions of the engine components are dictated according to the preburner properties. The optimization study and 1D numerical simulations by EcoSimPro have been performed for nine subsonic and supersonic Mach numbers, i.e. 0.5, 0.75, 0.9, 1.5, 2.0, 3.0, 4.0 and 4.5 [14].

Each flight condition resulted in different combination of pre-burner settings due to different operational needs at a given Mach number and altitude along the trajectory (Table 2). The results show that ATR engine air needs 
Table 3 Optimized pre-burner properties

\begin{tabular}{lllll}
\hline Mach no & $\begin{array}{l}A_{\text {throat }} \\
{\left[\mathrm{m}^{2}\right]}\end{array}$ & $\begin{array}{l}P_{\text {combustor }} \\
{[\mathrm{bar}]}\end{array}$ & $\begin{array}{l}\text { MR } \\
{[-]}\end{array}$ & $\begin{array}{l}\dot{m}_{\text {fuel }} \\
{[\mathrm{kg} / \mathrm{s}]}\end{array}$ \\
\hline 05 & 17.37 & 1.48 & 31 & 58.0 \\
0.75 & 17.37 & 2.5 & 45 & 74.5 \\
0.9 & 17.37 & 1.6 & 38 & 53.0 \\
1.5 & 17.37 & 1.5 & 30 & 59.2 \\
2.0 & 17.37 & 1.6 & 35 & 53.8 \\
3.0 & 14.43 & 1.8 & 36 & 50.7 \\
4.0 & 3.98 & 4.0 & 68 & 24.3 \\
4.5 & 2.80 & 6.6 & 44.9 & 35.8 \\
\hline
\end{tabular}

require the throat area to be at maximum limit up until it high supersonic Mach numbers from which the values strongly diminish. The majority of the air scooped diverted to the common nozzle through the bypass duct without experiencing combustion. The engine fuel burn rate varies proportional to the thrust requirements of the aircraft. The initial ascend phase requires higher fuel burn rates than the high Mach number part of the trajectory as the drag force the vehicle experiencing is significantly reduced at higher altitudes (Table 3).

\subsection{Enhanced Tank Efficiency and Enhanced Liquid Hydrogen Density}

Liquid hydrogen has a higher (three times higher) specific energy than hydrocarbon fuels. This implies that if liquid hydrogen is used more energy can be produced by burning it for the same amount of mass, if compared to hydrocarbon fuels. If we compare the same mission at Mach 8, using either liquid hydrogen or hydrocarbon fuel as propellant, we can say that the higher is the specific energy, the lower is the mass of propellant we need to accomplish the mission. For this reason, hydrocarbon fuels' specific energy can be a limiting factor for long-haul routes at high-speed. The exploitation of liquid hydrogen allows for dramatic improvements in performance.

However, LH2 has an unfavorable volumetric density. Current challenge is to increase the mass of LH2 per unit volume from 70 up to $90 \mathrm{~kg} / \mathrm{m}^{3}$ (see Fig. 9). This goal can be achieved further investigating the possibility to produce and store the so-called slush hydrogen. Slush hydrogen consists in a mixture of liquid and frozen hydrogen in equilibrium with the gas at triple point. The concept has been studied by NASA since the $90 \mathrm{~s}$ and specifically in the framework of NASP project. [15]

The combination of the unfavorable volumetric density and the low tank efficiency is a real challenge to guarantee long-haul routes without exceeding reasonable amount for the overall volume of the aircraft that shall still be able to

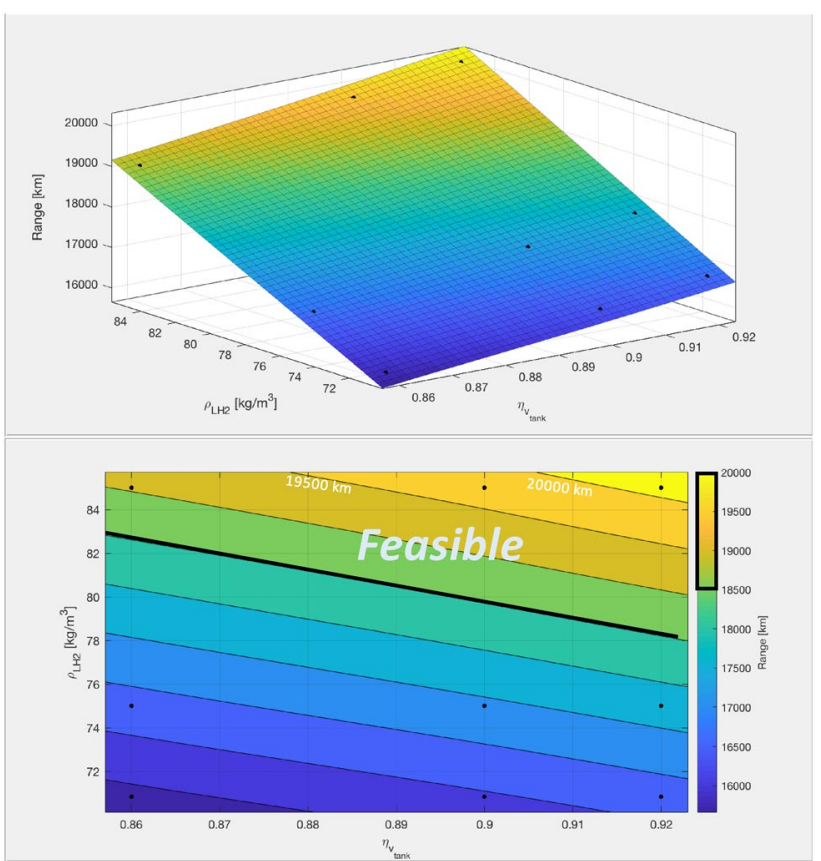

Fig. 9 Variation of range with respect to liquid hydrogen density and liquid hydrogen tan efficiency (top graph); variation of liquid hydrogen density with respect to liquid hydrogen tank efficiency (bottom graph)

take-off and land from/to existing ground infrastructures. Improvements both in terms of liquid hydrogen density and tank efficiency shall therefore be pursued.

STRATOFLY MR3 vehicle has an overall available volume of about $10,000 \mathrm{~m}^{3}$. Tanks occupy about $2700 \mathrm{~m}^{3}$ of volume. Considering enhanced tank efficiency and enhanced liquid hydrogen density, the aforementioned volume for the tanks guarantees the accomplishment of antipodal routes (about 19,000 km of range).

\subsection{More Efficient and Greener Propulsion Systems}

The DMR combustor design will be optimized to reduce NOx emissions, thanks to both engineering and CFD tools, and exploiting dedicated experiments to be performed at DLR-HEG facility.

CIRA carried out a Small Scale Flight Experiment numerical simulation selected for validation of CFD results with measurements (TC\#1478 at $\mathrm{Mach}=7.36, \mathrm{AoA}=-2^{\circ}$, $\mathrm{ER} \approx 1.04$, from LAPCAT-II project [3]), and to provide $\mathrm{NOx}, \mathrm{H} 2 \mathrm{O}$ at nozzle exhaust for setting up (and locate) a NOx measurement laser-based technology (TDLAS) to be used during the next HEG Test Campaign. ANSYS-Fluent ${ }^{\circledR}$ code was used as CFD solver, whereas chemical kinetics modeling (including NOx production mechanism by Zel'dovič) was inherited from LAPCAT-II CFD activities on. 
MR2.4 full-scale DMR combustor [3]. It is worth remembering that the propulsive flowpath is identical between LAPCAT II MR2.4 and STRATOFLY MR3 vehicles, so the Small-Scale model used for scramjet engine experiment is still used. CFD results on a 6.5-million elements unstructured grid are shown in Fig. 10.

From a detailed analysis of the predicted flow field, two different solutions (with corresponding Y-lines of sight with $\mathrm{NO}$ and $\mathrm{H} 2 \mathrm{O}$ concentrations) have been elaborated and proposed to DLR-HEG for the TDLAS measurement unit NO-probe location, see Fig. 11: solution A, inside the model's nozzle (to be windowed) and solution $\mathrm{B}$, in the free jet after the nozzle exhaust. $\Phi$ is a weighting function (equation reported in Fig.) defined to identify in the flow a suitable location (line of sight) for NOx measurement, for which NOx (due to only scramjet internal combustion) is maximum and water vapor content is the lowest possible.

For what concerns the engineering modeling of the MR3 vehicle's DMR engine (by means of EcoSimPro), CIRA has provided VKI with the flow conditions at the intake and isolator calculated by the SPREAD code [10], in the Mach number range from 4.5 to 8 , see the sketch of Fig. 12. Starting from the reference trajectory, 19 different high Mach number flight conditions (during the powered ascent and cruise, and the unpowered descent) have been calculated, to build up a database of intake performance (flow conditions at isolator, pressure recovery, intake efficiency, effect of altitude, etc.).

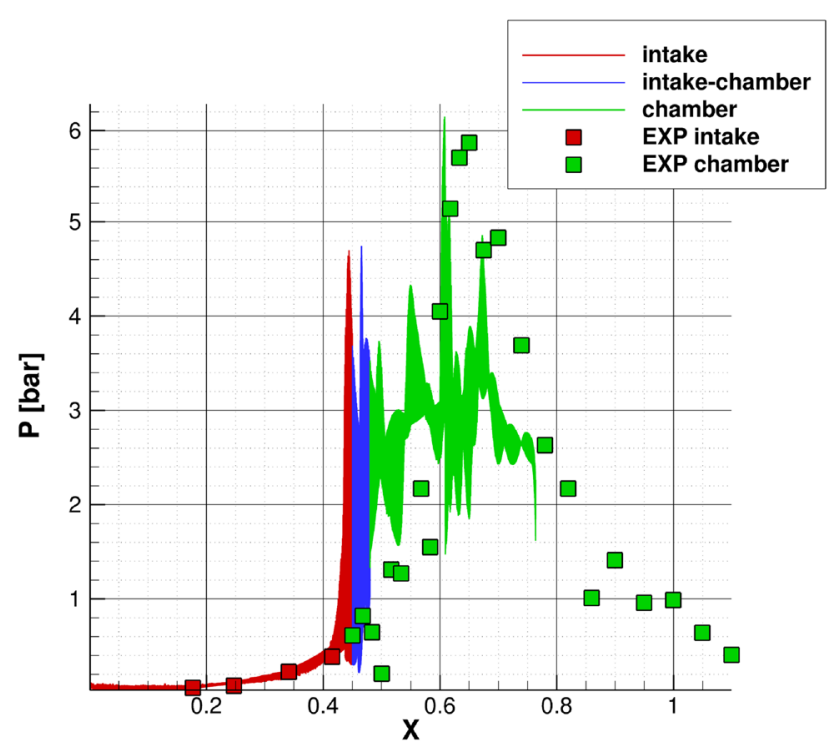

Fig. 10 CFD rebuilding of TC\#1478: pressure distribution along the propulsive flow path

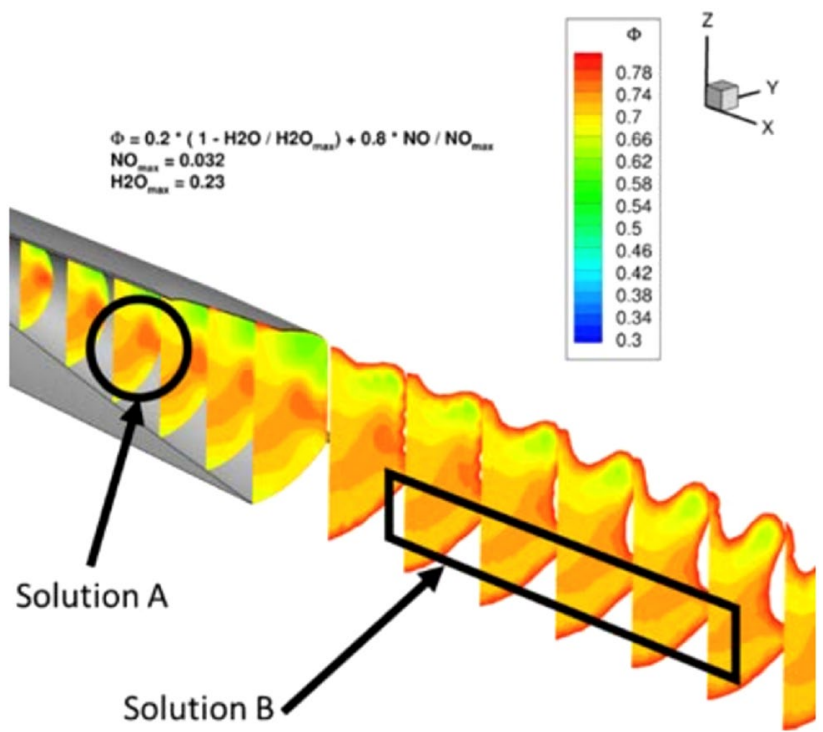

Fig. 11 CFD rebuilding of TC\#1478: solutions to locate NO-probe of TDLAS measurement

\subsection{Main Intake Configuration Performance}

The Thermal Protection System includes breakthrough innovative hot structures, based for example on innovative ceramic matrix composites (CMC) technology and heat pipes to cool leading edges, considering as cold source propellant tanks and as working fluid solid material at sea-level temperature.

CFD simulations have been performed on the intake geometry of Fig. 13 to find the best compromise for the leading edges rounding in terms of intake performance (captured mass flow rate, total pressure recovery) and thermal loads (heat fluxes in critical areas) [11].

The cruise condition at $M=8$ and $32 \mathrm{~km}$ of altitude has been considered, radiative equilibrium with surface emissivity of $\varepsilon=0.8$ has been applied and fully turbulent flow field has been modeled by means of $k-\omega$ SST modeling. Three values of the intake leading edge radii have been analyzed $(6.25,11.3$ and $22.5 \mathrm{~mm}$; same value for lower lip, lateral

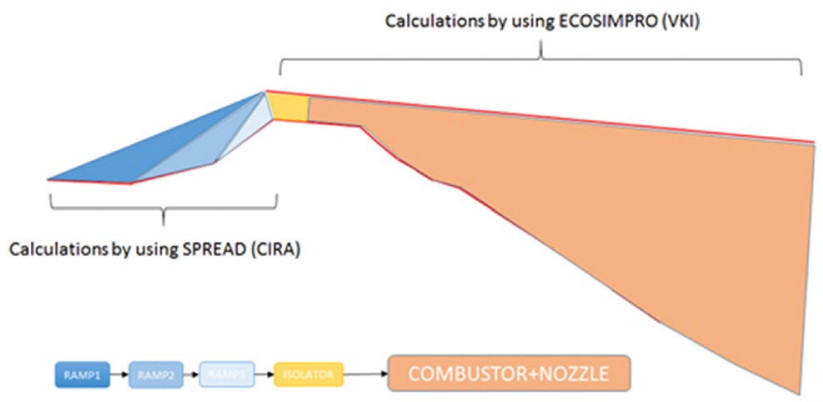

Fig. 12 MR3 DMR engine flowpath sketch 


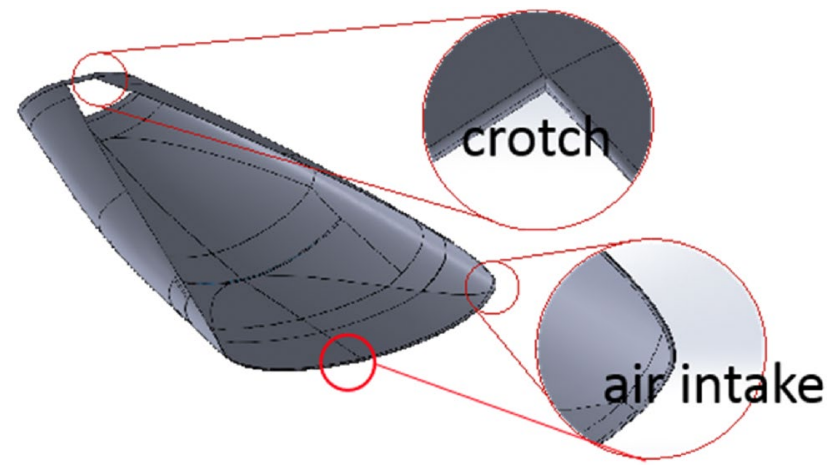

Fig. 13 STRATOFLY MR3 vehicle air intake leading edges and crotch modeling

edges and crotch) by means of ANSYS- Fluent ${ }^{\circledR}$ code on a reduced geometry domain including in addition to the intake the combustor part too.

Unstructured grids have been generated (20-30 millioncells), constituted of tetrahedral cells inside the bulk volume of the domain and of prisms near the solid surfaces to have a better boundary layer resolution.

Oblique shock waves start from intake geometry discontinuity and are all captured inside the crotch, while the leading edge shock goes just a little bit outside.

The interaction of local crotch bow shock and the oblique shock wave happens internally to the combustor inlet causing an overload with respect to the leading edge zone. The maximum of heat flux and temperature (hot point at crotch leading edge) is anyway located near the lateral leading edge junction and not on the symmetry plane. In this part of the geometry, there is a strong 3D interaction between the above said shocks with the transversal shock wave starting from the lateral leading edge (see Fig. 14).

The sensitivity analysis with respect to the leading edge radius is shown in Figs. 15, 16 and 17. The efficiency parameters of the air intake, mass flow rate and pressure recovery factor (PRF), decrease with respect to the radius, and the thermal loads that the material of the leading edge has to withstand show the same trend (Fig. 16), both at lower lip and crotch. In all three cases, the intake is able to capture correctly the air mass flow. Additional CFD simulations were performed in the intake's symmetry plane with the hypothesis of two-dimensional flow, whose results are clearly indicated in the figures with "2D" label in Fig. 15, and "LE HF 2D" and "LE Temp 2D" in Fig. 17.

Even though the efficiency of air mass flow decreases (max. 4\%) with leading edge radius, and the PRF decreases more than mass flow rate, the radius value of $11.3 \mathrm{~mm}$ seems to be a good compromise between two opposite trends, i.e. the positive decreasing of thermal loads and the negative decreasing of mass flow rate and total pressure at the entrance of the combustor.

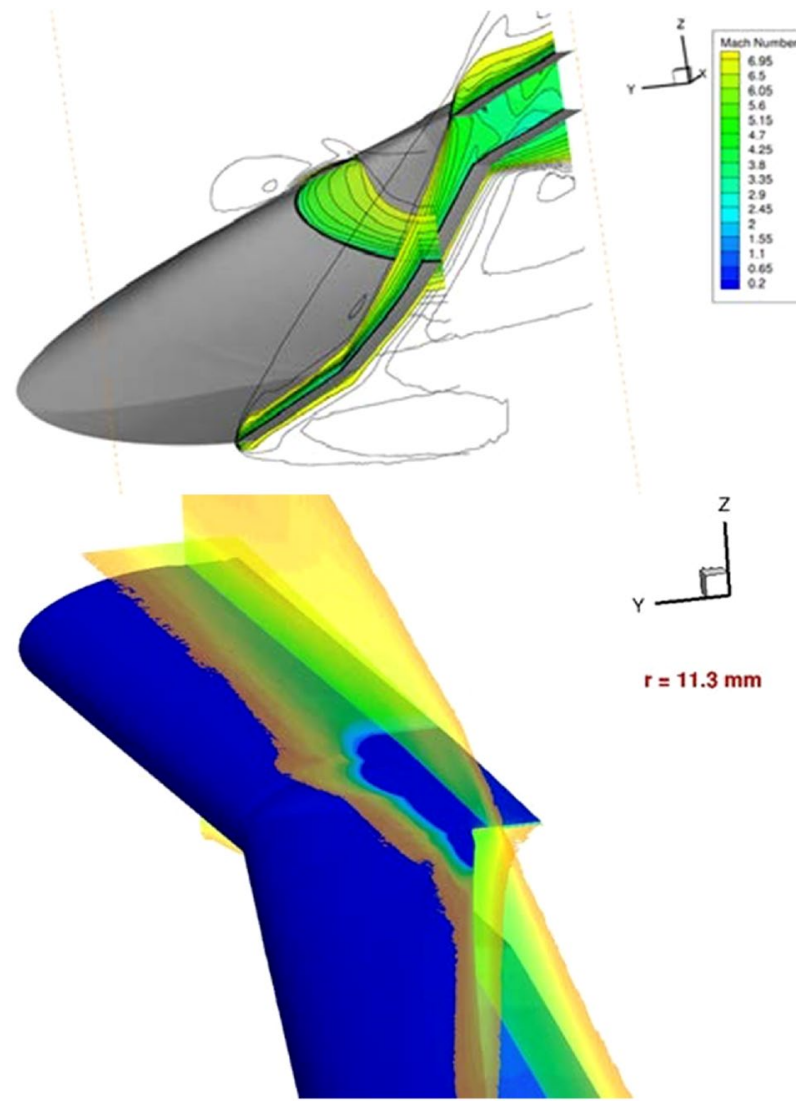

Fig. 14 CFD results for the $11.3 \mathrm{~mm}$ rounding: flow field in terms of Mach number (top) and hot point near the crotch's lateral junction (bottom)

It has also been verified that there is no significant effect of leading edge radius on the air-hydrogen supersonic combustion [11]. Note from Fig. 17 that the fluid dynamic behavior in the symmetry plane of the intake can be presumed as quasi-2D. It is important to remark that the values of heat flux and temperature at the hot point (off- symmetry) do not

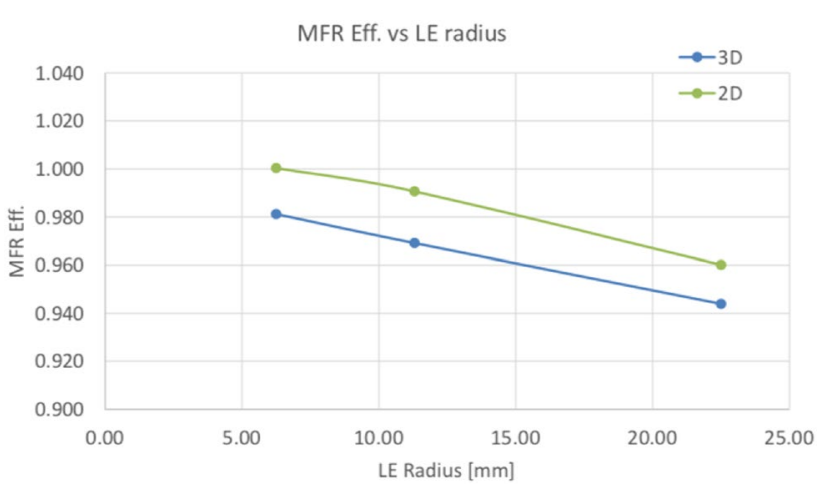

Fig. 15 Mass flow rate efficiency vs. leading edge radius 


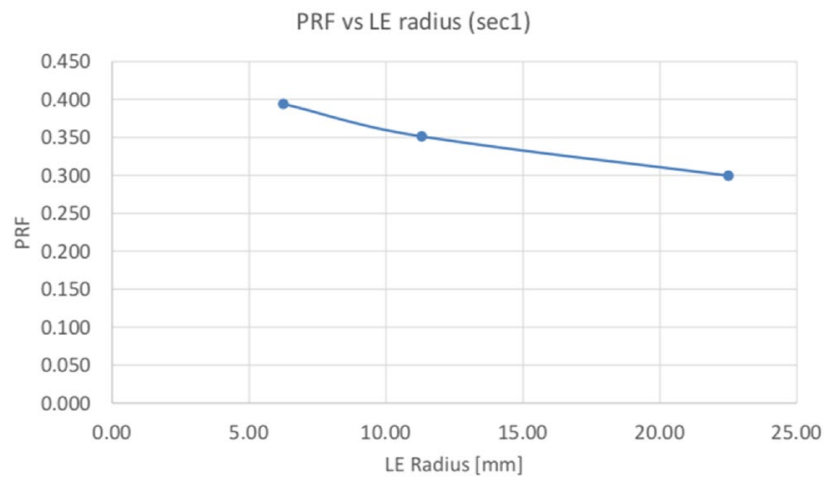

Fig. 16 Pressure recovery factor (PRF) vs. leading edge radius

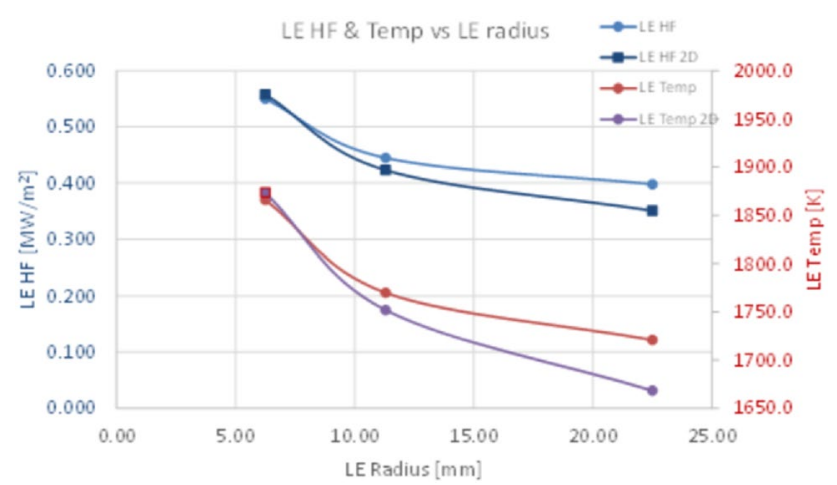

Fig. 17 Intake lower lip (symmetry plane) heat flux and temperature vs. leading edge radius

show a regular trend as for the leading edge and crotch leading edge (in the symmetry plane).

\subsection{Aerodynamic Database}

The aerodynamic database (AEDB) developed during the LAPCAT-II project [3], based on engineering methods, cross-checked by detailed CFD nose-to-tail simulations and used for the calculation of the MR2.4 vehicle reference trajectory, is being reviewed, assessed and completed, especially for what concerns: (1) the addition of the effects of (updated) control surface system in the low-supersonic to hypersonic regime (in charge of CIRA using their own surface impact method SIM, part of SPREAD code), and (2) the refinement of the subsonic to low-supersonic regime including again the effects of Flight Control System (in charge of Politecnico di Torino, using engineering methods).

It is worth highlighting that this new version of the AEDB refers to the MR3 vehicle external surfaces only, including the flight control system (elevators, ailerons, vertical tail), without accounting for the effects of the propulsive flowpath nor for the viscous effects.

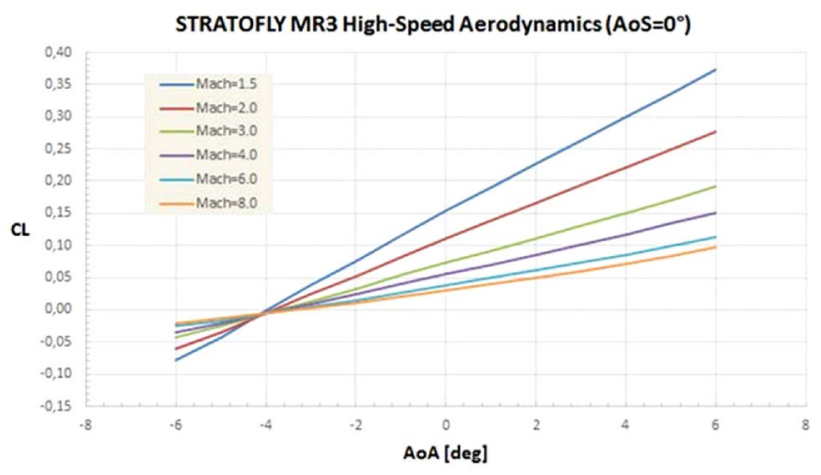

Fig. 18 MR3 lift coefficient CL vs. angle of attack AoA

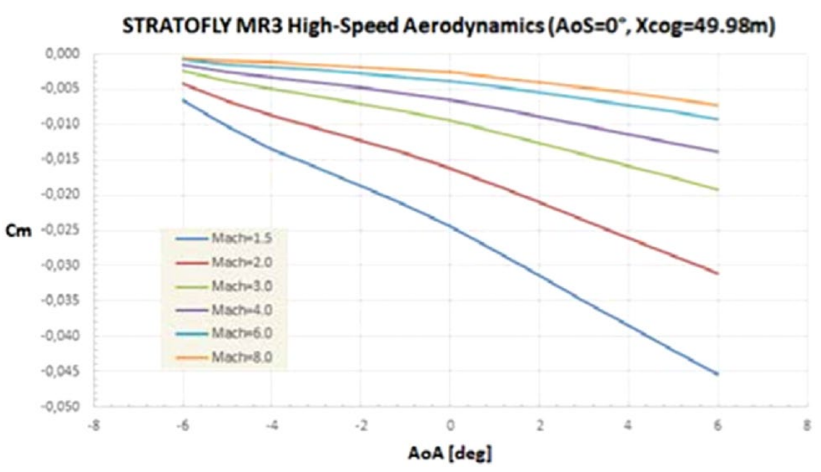

Fig. 19 MR3 pitching moment coefficient $\mathrm{Cm}$ vs. angle of attack AoA

Two test matrices have been calculated for the AEDB setup, in the hypothesis of no influence of angle of sideslip (AoS) on the effects produced by elevons (elevators, ailerons) and rudders deflected.

After tuning the surface impact method [10] with original MR2.4 AEDB and available CFD results by ESA and CIRA, the calculation strategy (tangent-wedge method for windside, Newtonian/Prandtl-Meyer expansion for leeside and fuselage) has been fixed and the computed results have been analyzed in terms of aerodynamic performance, static stability (both longitudinal and lateral directional), sensitivity to center of gravity $(\mathrm{CoG})$ movement, analysis of trimmability.

A collection of STRATOFLY MR3 AEDB results is shown in Figs. 18, 19, 20 and 21.

A linear behavior of lift coefficient CL in the AoA range is predicted, as well as a high lift-to-drag ratio of about 10 at AoA $=0^{\circ}$, as expected by a waverider configuration. Moreover, Mach number independence of aerodynamic coefficients is still not fully reached at Mach $=8$.

A clear longitudinal static stability $(\mathrm{Cm} \alpha<0)$ at all Mach numbers for both CoG values $(X=49.98 \mathrm{~m}$ with $20 \%$ fuel, $X=52.95 \mathrm{~m}$ with $100 \%$ fuel) is predicted, with a decrease of stability with Mach number and with more backward CoG 
STRATOFLY MR3 High-Speed Aerodynamics $\left(A \circ A=0^{\circ}\right)$

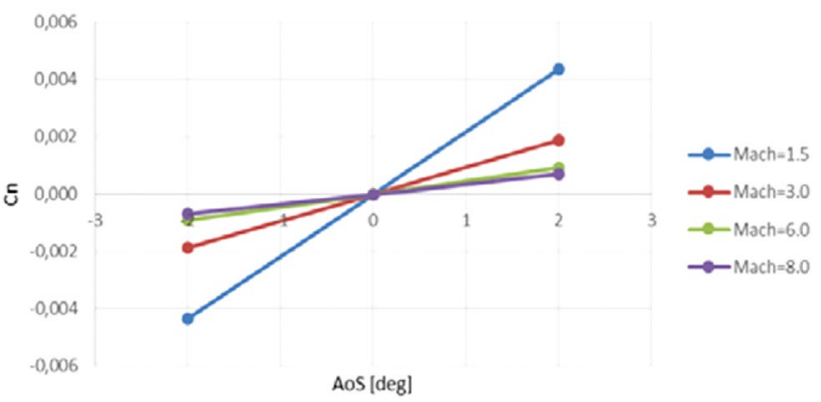

Fig. 20 MR3 yawing moment coefficient $\mathrm{Cn}$ vs. angle of sideslip AoS

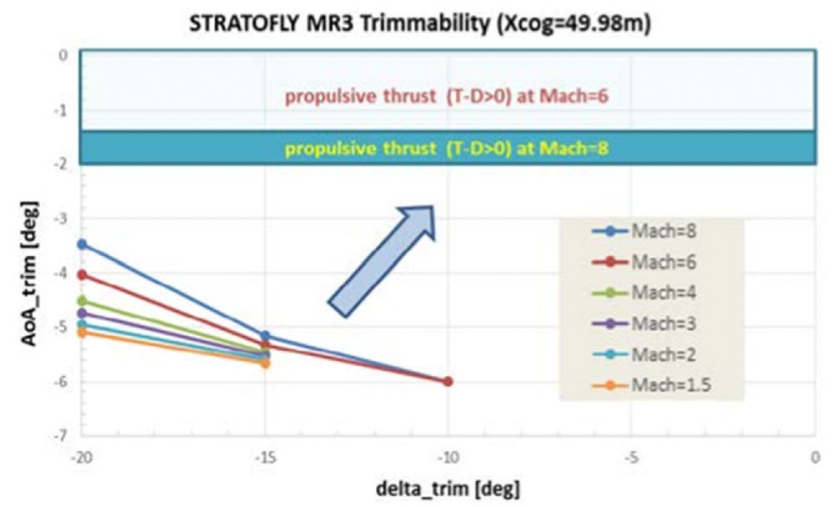

Fig. 21 MR3 trimmability map

position. It is clear the need for trimmability with negative elevon deflection for all flight conditions (large $\Delta \mathrm{Cm}$ to null, greater for lower Mach), thus confirming the conflicting requirements: stability vs. trimmability. Of course, in present working hypotheses, the beneficial engine-on effect on $\mathrm{Cm}$ (shift up of curve) is totally missing.

The MR3 vehicle clearly features a lateral-directional static stability, which, however, decreases with Mach number and is not affected by the full AoA range $\left[-6^{\circ} \div 6^{\circ}\right]$, and with a very small effect of $\mathrm{CoG}$ movement on lateral stability $(\mathrm{Cn} \beta>0)$.

The predicted trimmability map of the MR3 vehicle (for the more forward $\mathrm{CoG}$ position), always keeping in mind that we are dealing only with external surfaces (no propulsive flowpath accounted for, nor viscous effects), is shown in Fig. Considering also that the elevons' efficiency $(\mathrm{dCm} / \mathrm{d} \delta \mathrm{e})$ decreases for negative deflections as Mach number increases above 3 and the negative effect of more backward CoG (trim conditions only for $\delta \mathrm{e}=-20^{\circ}$ ), the trim AoA values are far from the optimum values emerged from the aero-propulsive analysis (based on detailed nose-to-tail CFD simulations [12]), i.e. maximum propulsive thrust for $\mathrm{AoA}=-2^{\circ} \div 0^{\circ}$ at $\mathrm{Mach}=6$ and $\mathrm{AoA}=-2^{\circ}$ at $\mathrm{Mach}=8$.
By the way, these are the results of the first design loop of the Flight Control System, and possible viable solutions to be investigated to get trim conditions for optimum propulsive thrust are: (1) evaluate the effect of propulsive flowpath and motor-on on trimmability, (2) enlarge the horizontal control surfaces, (3) reconsider the canard wings, (4) change the elevon airfoil shape, and (5) change the wing-body angle.

\subsection{Noise Reduction and Noise Suppression Strategies Based on Nozzle-Airframe Integration}

Noise is a crucial issue for high-speed flight, both for the passengers on board the aircraft and the people on ground. Main concern within the STRATOFLY project lies in noise effects due to high-speed jets affecting passengers in the cabin, which lays just below the propulsive system air duct, as depicted in Fig. 22.

With regard to the nozzle-airframe integration for noise suppression, NLR and VKI are in charge to devise novel noise suppression techniques, profiting of the embedment of high-speed propulsion units within the airframe.

A confinement of the high-speed jet offers possibilities for flow manipulation, noise absorbers and to tailor the shear layer thickness, making it possible to mitigate jet noise and/ or to shift its dominant frequencies. Additionally, the airframe integrated nozzle can act as an acoustic barrier or reflector between the jet and observer.

Within STRATOFLY, the jet noise during the take-off and landing is studied, when the DMR acts as a flow through channel without combustion and the aircraft is propelled by six ATR engines. These latter are installed in bypass ducts, three ATR engines in each bypass duct. Both the DMR and ATR bypass ducts exhaust in one single nozzle. Based on three-dimensional steady Navier-Stokes CFD simulations [12], a complex flow topology has been observed during the subsonic take-off and landing phases. In the threedimensional CFD [12] two relevant conditions for take-off are reported, with flight Mach number 0.3 and 0.5. These

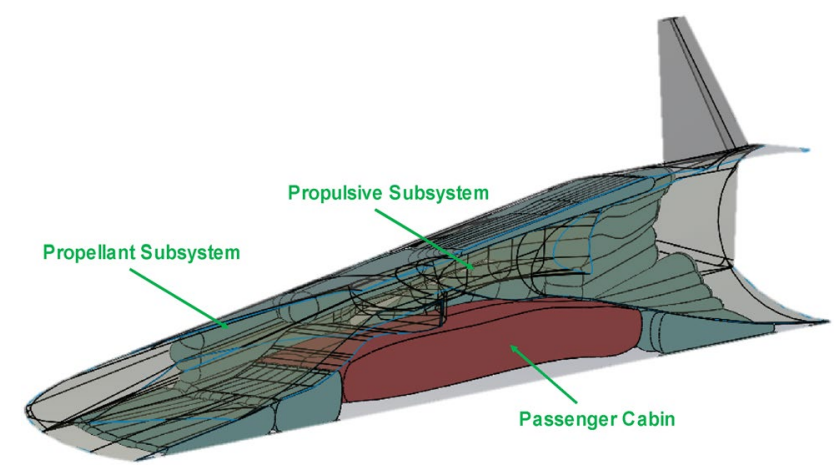

Fig. 22 Passenger cabin integration within the vehicle 
two conditions are characterized by the following key flow features that are believed to be important aspects when it comes to noise generation:

- Flight Mach number 0.3 condition: the exhaust jets from the ATR ducts merged with the flow through the DMR in the combined nozzle forming a high-speed (but still subsonic) jet which is separated from the combined diverging nozzle.

- Flight Mach number 0.5 condition: the exhaust jets from the ATR ducts merge with the flow through the DMR in the combined nozzle. A combined flow is formed which tries to follow the diverging nozzle contour. For a short distance, the flow accelerates, but quickly it separates. After separation, a normal shock is formed and the flow decelerates.

A simplified coaxial axi-symmetric laboratory scale nozzle has been designed and manufactured (see Fig. 23), capturing the believed to be key noise generating flow features of the real geometry.

For example, at the flight Mach number 0.5 condition, formation of shocks within the nozzle is observed due to the aerodynamic effect of the nozzle. Confining the jet with an airframe integrated nozzle can therefore introduce noise sources otherwise absent in an unshrouded jet. This effect can be seen in Fig. 24, showing a CFD inviscid flow field. The top half of the figure shows a shortened version of the coaxial axi-symmetric nozzle with respect to the lower half. The nozzle introduces a normal shock within the core flow with oblique shocks forming in the outer flow. When the nozzle is shortened, the shock formations are absent. Therefore, the integration of the nozzle within the airframe creates opportunities for noise suppression at the expense of possible introduction of new noise sources at some operating conditions, this net effect having to be evaluated. The laboratory setup allows for shortening the nozzle, thus evaluating

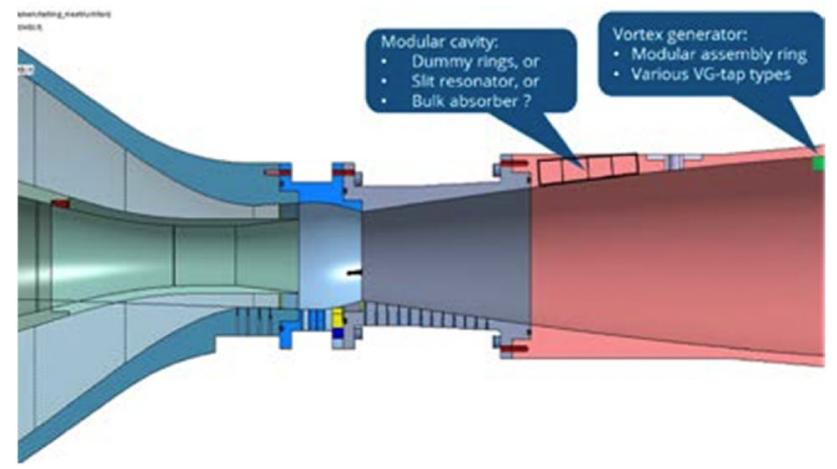

Fig. 23 Simplified coaxial axi-symmetric laboratory scale nozzle used for acoustic testing the net acoustic effect of confining the jet with the airframe integrated nozzle.

A preliminary inventory of possible noise reduction concepts has been made, with benefits and drawbacks with respect to the present application.

As far as the noise effects on the people on ground, in compliance with current International regulations for sonic boom issues, only oversea routes have been considered (see Fig. 25) so far sonic but new city-pairs connected by overland routes may be considered, after detailed investigations about sonic boom noise effects when flying at about $30,000 \mathrm{~m}$.

\subsection{Novel Multi-functional on-Board Energy and Thermal Management System}

Apart from a traditional TPS and a careful selection of materials, other strategies shall be considered to control the

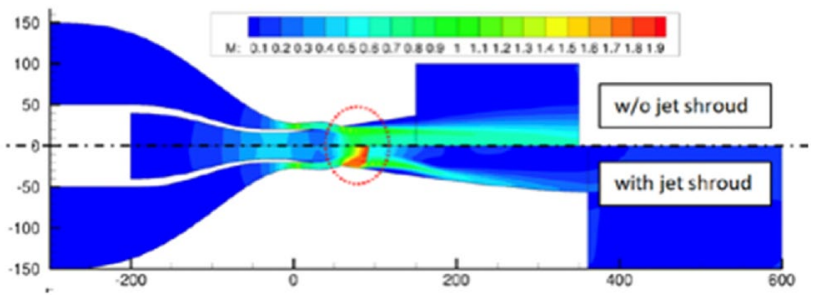

Fig. 24 CFD analysis of the simplified coaxial axi-symmetric laboratory scale nozzle

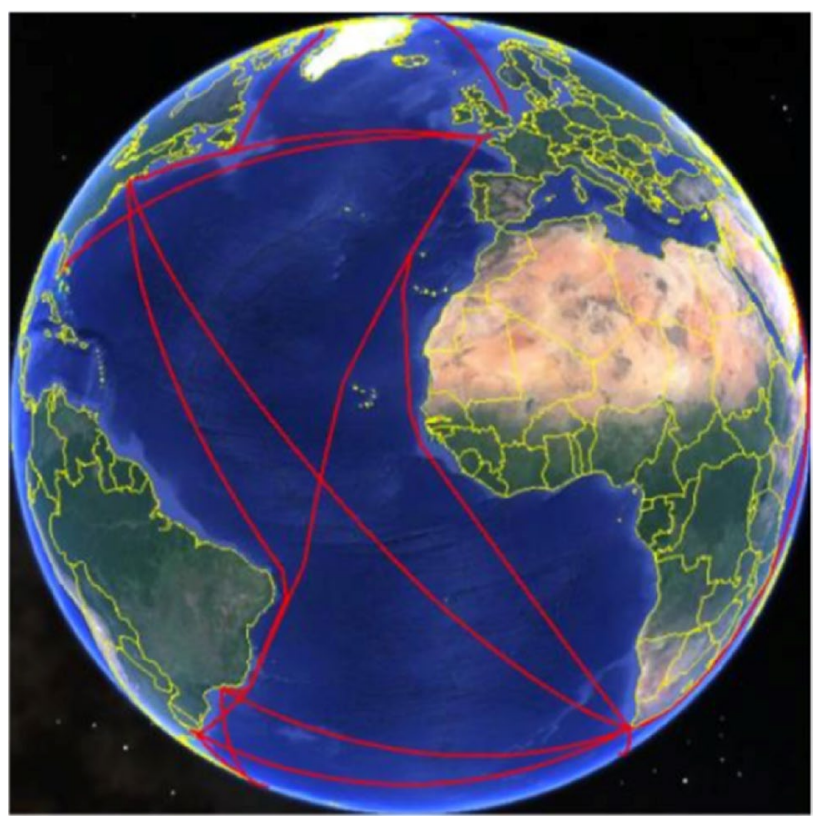

Fig. 25 STRATOFLY MR3 oversea routes 
amount of heat flowing through the shell into the internal compartment, to guarantee proper survivability levels of all the subsystems and payload. To face this problem, the MR3 vehicle is equipped with the innovative Thermal and Energy Management Subsystem (TEMS), whose scheme is shown in Fig. 26, which has been conceived since the LAPCAT-II project [3]. This subsystem exploits the boil-off vapors coming from the evaporation of the liquid hydrogen within the tanks as main coolant means for the cabin, the power-plant and the air-pack of the Environmental Control System (ECS), being finally injected in the combustor of the engines. Moreover, the high-pressure hydrogen is used to drive a dedicated turbine providing mechanical power to the devices of the TEMS itself, producing enough power margin for the other on-board subsystems. Tanks and cabin are in fact highly integrated in a bubble-structure architecture, which characterize the overall internal configuration of the waverider.

The Thermal and Energy Management Subsystem is a clear example of an innovative multi-functional and multidisciplinary subsystem combining the management of thermal loads and the electric power generation and

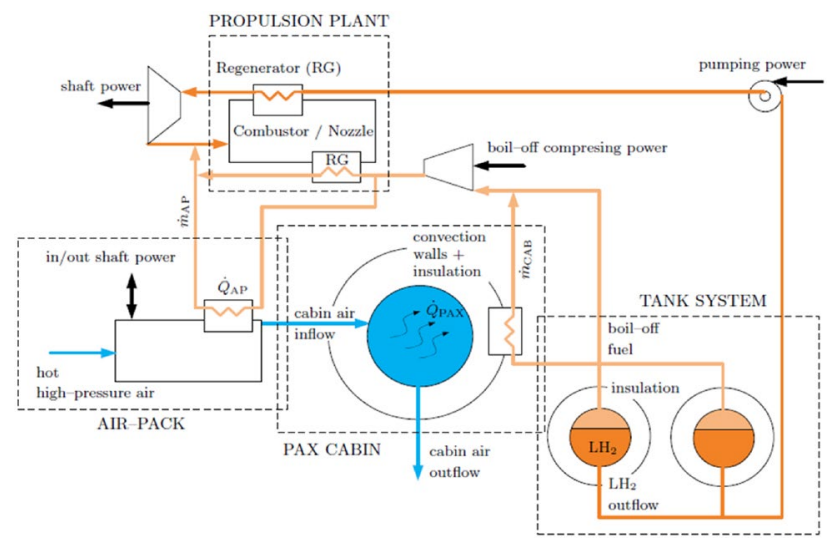

supply, making benefits of liquid hydrogen boil-off, that is usually considered a drawback. The high level of innovation, the complexity of the TEMS and its constituent components, the low maturation levels of the technologies as well as the integration on-board the reference vehicle need to be further investigated to confirm the technical feasibility of the concept. Thus, the development of a proper design methodology has been considered appropriate to size the main components of this highly integrated subsystem, developing dynamic models able to estimate the geometrical characteristics and mass, volume and power budgets of the elements, on the basis of the most demanding operational parameters.

Static models developed by Politecnico di Torino [13] have been used at the beginning of the STRATOFLY project to perform a preliminary mass, volume and power budgets estimation, considering the Mach 8 cruise as the most demanding condition. Then, these models have been integrated into a more complex dynamic model with the purpose of widening the investigation to verify the behavior of the subsystem along the entire mission.

Table 4 summarizes the operating conditions of the TEMS of STRATOFLY MR3 vehicle.

Thanks to the exploitation of the overall dynamic model, it is now possible to investigate the behavior of each single components of the TEMS and verify whether the proposed solution is in line with the vehicle's needs. As example, Figs. 27 and 28 report the compressor and turbine performance maps: from their operating lines it stems out that the components are well-sized for the operating conditions under evaluation. Eventually, thanks to the dynamic model, it is also possible to check the behavior of the overall TEMS, looking for example at the main power demand or at the overall available boil-off, see Fig. 29 [17].

Fig. 26 Thermal and energy management system

Table 4 TEMS expected operating conditions

\begin{tabular}{|c|c|c|}
\hline $\begin{array}{l}\text { Rotational speed } \\
N \text { [rpm] }\end{array}$ & {$[10000-40000]$} & $\begin{array}{l}\text { Considering a typical range of operations for turbopumps } \\
\text { with LH2 working fluid }\end{array}$ \\
\hline $\begin{array}{l}\text { Flow rate } \\
\dot{m}[\mathrm{~kg} / \mathrm{s}]\end{array}$ & {$[0-100]$} & \\
\hline $\begin{array}{l}\text { Fluid density } \rho \\
{\left[\mathrm{kg} / \mathrm{m}^{3}\right]}\end{array}$ & 70.8 & Liquid hydrogen (LH2) \\
\hline $\begin{array}{l}\text { Pressure rise } \\
\Delta p\left[\mathrm{~N} / \mathrm{m}^{2}\right]\end{array}$ & {$\left[60 \times 10^{5}-80 \times 10^{5}\right]$} & \\
\hline Efficiency $[-]$ & 0.7 & Assumption considering currently available technologies \\
\hline Turbopump type & $\begin{array}{l}\text { Radial pump and axial turbine con- } \\
\text { figuration }\end{array}$ & Considering the Balje and Cordier diagrams \\
\hline Mechanical arrangement & Direct driven & Depending on the speed variations between pump and turbine \\
\hline
\end{tabular}




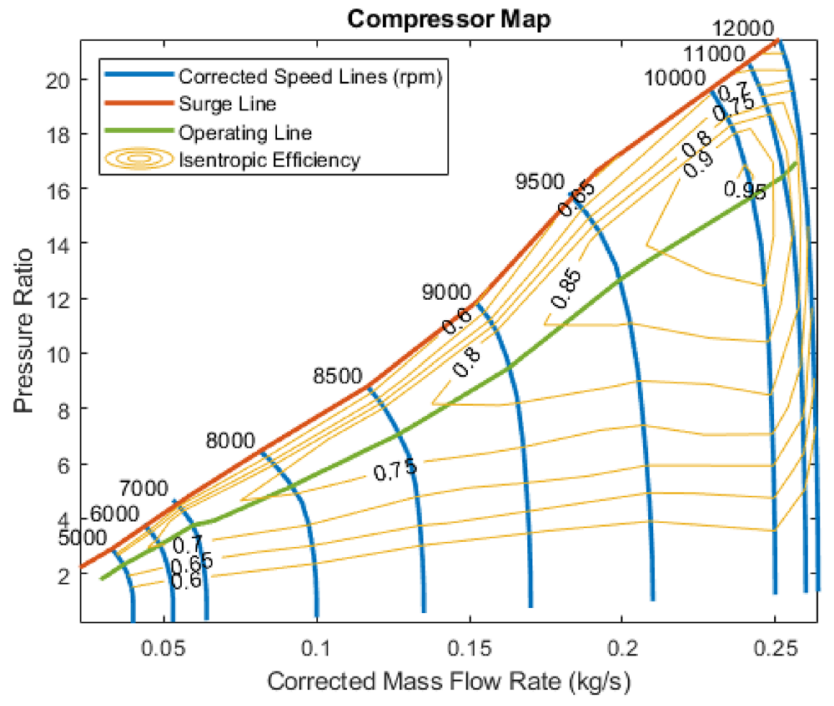

Fig. 27 TEMS compressor map
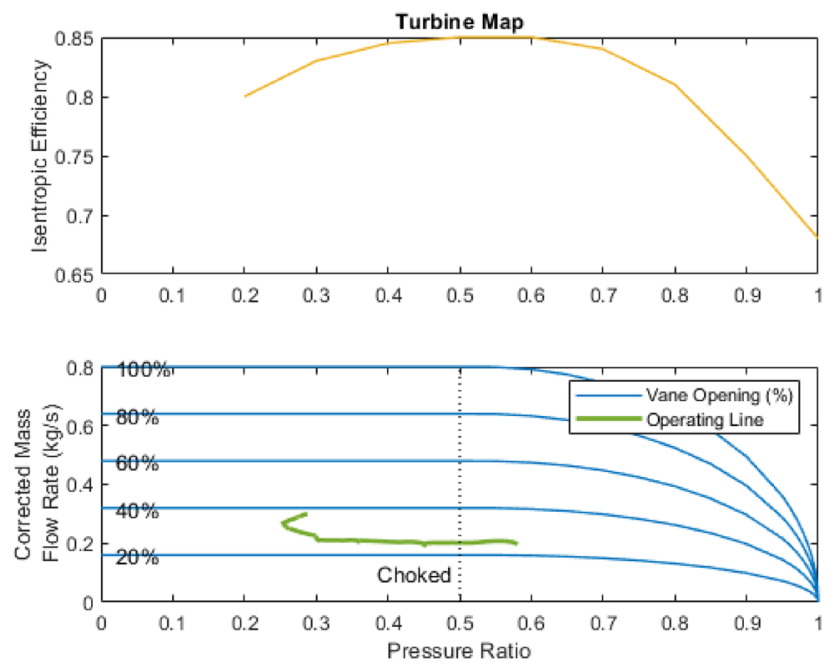

Fig. 28 TEMS turbine map

\section{Conclusions}

The STRATOFLY MR3 vehicle's current evolution is described in this paper, in particular for what concerns the main technical challenges and goals.

The formulation of the optimization problem for the airframe definition has been defined, in the context of a multi-disciplinary and multi-objective optimum design. Data flow exchange has been also suggested to a Pareto Front providing the designer with the information to carry out trade-off studies, thus combining efficiently each objective function in the selected design.

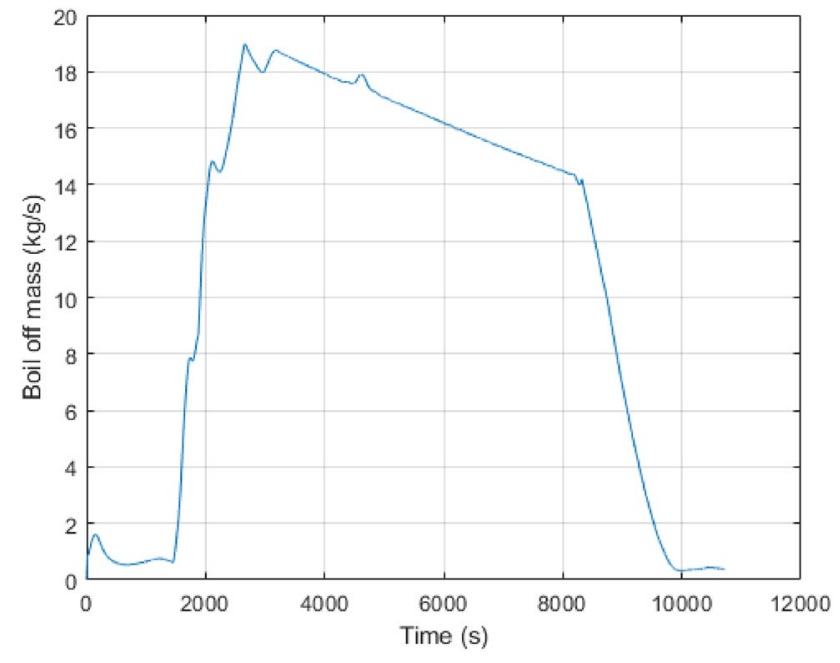

Fig. 29 TEMS boil-off all along the mission

A one-dimensional propulsion model for MR3 vehicle's propulsion plant has been built in EcoSimPro, to estimate combined ATR and DMR engines performance along the subsonic cruise and supersonic acceleration, coupled with the optimization tool CADO, to achieve optimal boundary and operational conditions for the best performance values, i.e. specific thrust and impulse at minimum fuel consumption.

A simplified coaxial axi-symmetric laboratory scale nozzle has been designed and manufactured, capturing the expected key noise generating flow features of the real nozzle geometry.

This nozzle will be experimentally tested in the NLR acoustic wind tunnel. The laboratory scale nozzle allows for shortening the nozzle to evaluate the net acoustic effect of confining the jet with the airframe integrated nozzle.

From a detailed analysis of the predicted flow field of the small-scale DMR model, two different solutions (with lines of sight for $\mathrm{NO}$ and $\mathrm{H} 2 \mathrm{O}$ concentrations) have been elaborated for the TDLAS measurement unit NO-probe setup, to be used during the next HEG test campaign at DLR.

After a detailed trade-off study, the radius of $11.3 \mathrm{~mm}$ for all the MR3 vehicle's main intake leading edges has to be considered as feasible and a good compromise between thermal loads and air intake efficiency.

The first design loop of the flight control system of MR3 has produced a first sizing of elevons and vertical tail: $60 \mathrm{~m}^{2}$ of horizontal surfaces (split in 4 devices, 2 by each side) and $2 \times 96 \mathrm{~m}^{2}$ of vertical tail. The aerodynamic analysis (external surfaces only, no propulsion effect) has shown that longitudinal trim AoA values are far from the optima emerged from the aero-propulsive analysis, so first viable solutions could be to enlarge horizontal control surfaces and/or reconsider the original canard wings. 
In any case, the MR3 vehicle features a high lift-to-drag ratio around $\mathrm{AoA}=0^{\circ}$, a clear longitudinal stability at all Mach numbers for both CoG assumed values, a decrease of longitudinal stability with Mach number and with the more backward CoG, a clear lateral-directional static stability, decreasing with Mach number, and a lateral stability not affected by CoG's assumed variation.

Concerning the on-board subsystems, STRATOFLY project is facing many crucial aspects to allow a high-level of integration within the airframe as well as to guarantee the requested level of performance. The first results of a set of dynamic simulations of the TEMS have confirmed the overall structure of the original architecture of the subsystem. In the second half of the project, thanks to updated results of the project itself (e.g. optimized trajectory, upgraded propulsive subsystem model, etc.), an upgrade of inputs and implemented models will be performed, and a new set of TEMS simulations' results will be provided.

Future activities include the further improvement of the technical issues here described, the design of the other onboard subsystems, like the Environmental Control Subsystem, the Electric Power Subsystem, the Landing Gear and the Avionics, and the thorough analysis of the concept of operations throughout all mission phases to understand if STRATOFLY MR 3 fits within the operational procedures for the current airport infrastructures. The analysis of all mission phases is a crucial issue for the STRATOFLY Project not only from the point of view of the operations but of course also from the point of view of the technical performance of each discipline. For the first time in fact with respect to the previous high-speed projects, in addition to the Mach 8 cruise condition, also the other flight phases will be tackled and a deeper investigation of the behavior of the aircraft aerodynamics and the propulsive system (including emission) in subsonic, transonic and low-supersonic phases will be analyzed through low and high fidelity simulations. Moreover, test campaigns for noise mitigation, supersonic combustion with and without Plasma Assisted Combustion and emissions measurement at hypersonic speed will be performed and the data package will be crucial to validate new simulation models.

STRATOFLY MR3 has the ambitious goal of satisfying the need that urges Europe to shorten the time of flights for long-haul routes and at the same time to move toward a more sustainable aviation from the environmental point of view: zero $\mathrm{CO}_{2}$ emissions are guaranteed thanks to the exploitation of liquid hydrogen and $\mathrm{NO}_{\mathrm{X}}$ emissions as well as noise shall be mitigated.

Acknowledgements The H2020 STRATOFLY Project has received funding from the European Union's Horizon 2020 research and innovation programme under Grant Agreement No. 769246.
Funding Open access funding provided by Politecnico di Torino within the CRUI-CARE Agreement.

\section{Declarations}

Conflict of interest On behalf of all authors, the corresponding author states that there is no conflict of interest.

Open Access This article is licensed under a Creative Commons Attribution 4.0 International License, which permits use, sharing, adaptation, distribution and reproduction in any medium or format, as long as you give appropriate credit to the original author(s) and the source, provide a link to the Creative Commons licence, and indicate if changes were made. The images or other third party material in this article are included in the article's Creative Commons licence, unless indicated otherwise in a credit line to the material. If material is not included in the article's Creative Commons licence and your intended use is not permitted by statutory regulation or exceeds the permitted use, you will need to obtain permission directly from the copyright holder. To view a copy of this licence, visit http://creativecommons.org/licenses/by/4.0/.

\section{References}

1. Langener, T., Erb, S., Steelant, J.: Trajectory simulation and optimization of the LAPCAT-MR2 hypersonic cruiser concept. In: Proceedings of the 29th congress of the international council of the aeronautical sciences, St. Petersburg, Russia, September (2014).

2. Steelant, J.: ATLLAS: aero-thermal loaded material investigations for high-speed vehicles. In: 15th AIAA international space planes and hypersonic systems and technologies conference (2008).

3. Steelant, J., Varvill, R., Defoort, S., Hannemann, K., Marini, M.: Achievements obtained for sustained hypersonic flight within the LAPCAT-II project. In: 20th AIAA international space planes and hypersonic systems and technologies conference, Glasgow, Scotland, AIAA, pp. 2015-3677 (2015).

4. Blanvillain, E., Gallic, E.: HIKARI: paving the way towards high speed air transport. In: 20th AIAA international space planes and hypersonic and technologies conference, Glasgow, Scotland (2015).

5. Steelant, J., et al.: Conceptual design of the high-speed propelled experimental flight test vehicle HEXAFLY. In: 20th AIAA international space planes and hypersonic systems and technologies conference, Glasgow, Scotland (2015).

6. Favaloro, N., et al.: Design analysis of the high-speed experimental flight test vehicle HEXAFLY international. In: 20th AIAA international space planes and hypersonic systems and technologies conference, Glasgow, Scotland (2015).

7. Moral, J., Pérez Vara, R., Steelant, J., De Rosa, M.: ESPSS simulation platform. In: Space propulsion conference 2010, San Sebastian, Spain, May (2010)

8. Villacé, V.F.: Simulation, design and analysis of air-breathing combined-cycle engines for high speed propulsion. Ph.D Dissertation, Escuela Tecnica Superior de Ingenieros Aeronauticos, Univ. Politécnica de Madrid (2013).

9. Verstraete, T.: CADO: a computer aided design and optimization tool for turbomachinery applications. In: 2nd International conference on engineering optimization, Lisbon, Portugal, pp. 6-9, September (2010). 
10. Piscitelli, F., Cutrone, L., Pezzella, G., Roncioni, P., Marini, M.: Nose-to-tail analysis of an airbreathing hypersonic vehicle using an in-house simplified tool. Acta Astronaut. 136, 148-158 (2017)

11. Roncioni, P., Marini, M., Saccone, G., Fusaro, R., Viola, N.: Preliminary numerical characterization of STRATOFLY vehicle's intake. In: International conference on flight vehicles, aerothermodynamics and re-entry missions and engineering, Monopoli, Italy, 30 Sept-3 Oct (2019).

12. Krempus, D.: Evaluation of the aero-propulsive performance of a hypersonic aircraft during the acceleration phase. Master Thesis, ITLR Univ. Stuttgart, April (2017).

13 Fusaro, R., Ferretto, D., Viola, N., Villace, V., Steelant, J.: A methodology for preliminary sizing of a thermal and energy management system for a hypersonic vehicle. Aeronaut. J. (2019). https://doi.org/10.1017/aer.2019.109

14. Goncalves P., Ispir A.C., Saracoglu B.H.: Development and optimization of a hypersonic civil aircraft propulsion plant with regenerator system. In: AIAA Propulsion and Energy Forum 2019, Indianapolis, IN, AIAA-2019-4421 (2019)
15 Gürsu, S., Sheriff, S.A., Vezirocğlu, T.N., Sheffield, J.W.: Review of slush hydrogen production and utilization technologies. Int. J. Hydrogen Energy 19(6), 491-496 (1994). https://doi.org/10.1016/ 0360-3199(94)90002-7

16. Struempfel, C., Lehmann, O.: Challenges and potentials of aircraft noise modeling using enhanced aircraft performance parameters and flight deck procedures. In: Technische Universität Berlin, Germany conference: INTER-NOISE 2017-46th international congress and exposition on noise control engineering (2017).

17. Fusaro, R., Ferretto, D., Viola, N., Villace, V.F., Steelant, J.: A methodology for preliminary sizing of a thermal and energy management system for a hypersonic vehicle. Aeronaut. J. 123(1268), 1508-1544 (2019). https://doi.org/10.1017/aer.2019.109

Publisher's Note Springer Nature remains neutral with regard to jurisdictional claims in published maps and institutional affiliations. 